\title{
Profile of burns cases among children treated at a tertiary care hospital
}

\author{
K Padmakumar', Issac $\mathrm{NJ}^{2}$, Mukundan PK ${ }^{3}$, Kuttichira Praveenlal', Gnanadurai Angela ${ }^{5}$ \\ Received on October 31, 2018; editorial approval December 18, 2018
}

\begin{abstract}
Introduction: Epidemiological data on burns in children can give valuable information to policy makers for developing prevention strategies in reducing the incidence of childhood burns. Objectives: To study the Profile, manner and outcome of burns cases among children treated at a tertiary care hospital. Materials and methods: A Retrospective observational study was conducted based on medical records of children below the age of 12 years with the diagnosis of acute burns admitted to Jubilee Mission Medical College Hospital during 01-07-2016 to 30-06-2017. Results: A total of 169 burn cases were treated during the study period, of which 61 were children below 12 years. Maximum numbers of affected children were from the age group of less than 4 years and 60 cases were of accidental in nature. Scalding was the predominant cause of injuries and often related to cooking practices. No cases were reported with more than 30\% burns and there was no mortality. Conclusion: Burn injuries can be reduced by bringing about regulations to develop safer cooking practises and educating the community especially the women on safe practises at home and also on first aid measures.
\end{abstract}

Keywords: Accidental burns; Child abuse; homicidal burns.

\section{INTRODUCTION}

The term Burn denotes an injury to the skin or other organic tissue primarily caused by heat or due to radiation, radioactivity, electricity, friction or contact with chemicals.

Over the past several decades incidence of burns, burns related admissions, burns related morbidity \& mortality have decreased by nearly $50 \%$ due to different legislations, health promotion, appliance design, advanced burn care and a better understanding of fluid resuscitation and aggressive surgical management. Despite all these developments, burns remain a leading cause of morbidity and mortality. ${ }^{1}$ Incidence of burn injuries varies greatly between cultures and it is a global public health problem accounting for an estimated 2,65,000 deaths annually. The majority of these occur in low- and middleincome countries and almost half occur in south East Asia region.

In India over $10,00,000$ people are moderately or severely burnt every year. ${ }^{2}$ According to most recent data females and males have broadly similar rates for burns but there is a higher risk for females. Along with adult woman, children are particularly vulnerable to burns. Burns are the eleventh leading cause of death of children aged 1 to 9 years and also the fifth most common cause of non-fatal childhood injuries. ${ }^{2}$ Men are likely to suffer from burns in the work places while children and woman are usually suffered in domestic places. In children a major risk is improper adult supervision but a considerable number of burns in children result from child maltreatment also. Even though most of the child hood burns are accidental, child abuse also does occur. Nationally approximately $10 \%$ of child abuse cases involve burning, and up to $20 \%$ of paediatric burns admissions involve abuse or neglect. ${ }^{3}$ A hospital based retrospective study conducted

\footnotetext{
Address for correspondence:

${ }^{1}$ Professor

Mobile: +919846890060

Email: pkkidangoor@yahoo.com

Forensic Medicine\& Toxicology

${ }^{2}$ Assistant Professor (Corresponding author)

Mobile: +918872375699

Email: navienjohn@gmail.com

${ }^{3}$ Associate Professor of Plastic Surgery and Burns

${ }^{4}$ Principal and Professor of Psychiatry

Jubilee Mission Medical College \& Research Institute, Thrissur-680005.

${ }^{5}$ Principal, Jubilee Mission College of Nursing, Thrissur.
} 
in India during the year 1992 - 2017, showed 9.3\% burn injuries were secondary to abuse. ${ }^{4}$

Burns represent an extremely stressful experience for both the burn victims and as well as their families. Paediatric burns can have long term physical, psychological, economic and social implications for the patients and their families with on-going treatment, rehabilitation and the need for regular interventions.

Epidemiological study is an important modality to analyse the cause, magnitude and profile of burn in a particular region and population. Epidemiological data on burns in children can provide vital information for developing prevention strategies, through which the incidence of burns can be reduced. We do not have a recent and reliable data on the exact magnitude of burn injuries among children in this region. Hence a retrospective observational study is designed to get a data for this region.

Objectives are to study the profile of burn cases treated at Jubilee Mission Medical College Hospital in children below 12 years; to find out the mode and manner of infliction of burn injury and to study the distribution and outcome.

\section{MATERIALSAND METHODS}

It was a retrospective observational study. Medical records of patients with the diagnosis of acute burns admitted to Jubilee Mission Medical College Hospital during 01-07-2016 to 30-06-2017(one year) were reviewed. All cases of burns among children below the age of 12 years were included whereas burns cases above the age of 12 years were excluded.

Data collection and analysis: The patient's data were collected in a pre-structured proforma. Data collected were age, gender, mode of infliction, manner of infliction, distribution of burns and final outcome. Standard Lund and Browder charts as appropriate for patient age were used for rapid assessment of Total Body Surface Area (TBSA) involved. Data were analysed using Microsoft excel and results were presented with frequency and percentage and illustrated with charts and tables.

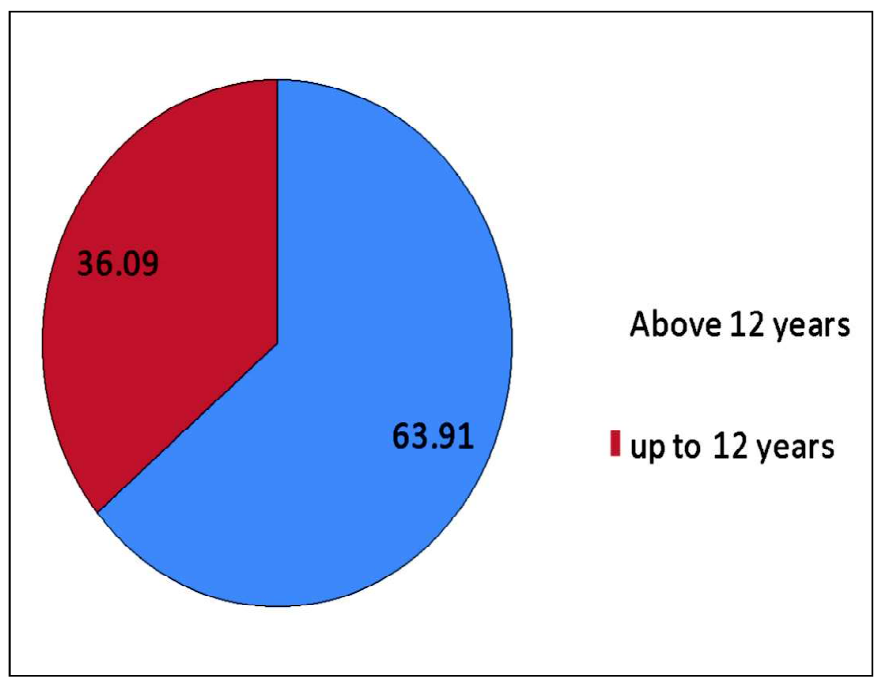

Figure 1 Distribution of cases

\section{RESULTS}

A total of 169 burn cases were treated in Jubilee Mission Medical College Hospital, Thrissur during the study period. Out of 169 cases, 61(36.09\%) were children below 12 years as shown in Figure 1.

Among the 61 cases, 35(57.38\%) were male children and $26(42.62 \%)$ were female children. The children were categorized in to three groups (up to 4 years, 5 to 8 years and 9 to 12 years) and the number of cases in each group is shown in Figure 2.

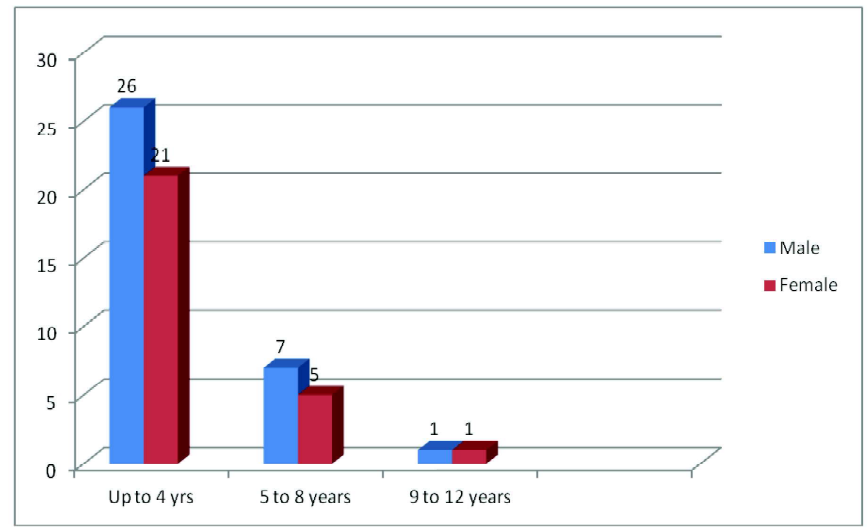

Figure 2 Age wise distribution of cases

Table 1 Source of burns in accidental cases

\begin{tabular}{|l|l|l|}
\hline Source of burn & No: of cases & Percentage \\
\hline Spillage of boiled water & 25 & 41.67 \\
\hline Spillage of hot beverages & 15 & 25.00 \\
\hline Crackers & 5 & 08.33 \\
\hline Burning of clothes & 4 & 06.67 \\
\hline Fall in to hot water & 4 & 06.67 \\
\hline Hot Cooking oil & 3 & 05.00 \\
\hline Dipping of hands in hot water & 3 & 05.00 \\
\hline Contact with hot tar & 1 & 01.66 \\
\hline & 60 & 100.00 \\
\hline
\end{tabular}

Table 1 depicts manner and source of burns. Out of the 61 cases, the manner of burns was accidental in nature in 60 cases. Scalding was the predominant cause of injuries and the source of burns in alleged accidental cases is shown in Only one case was reported as homicidal in which the father set ablaze a 12 year old female child.

All the ten victims of flame burns were male children and they were above the age group of 5 years.

Assessment of Total Body Surface Area (TBSA) involved was calculated and the patients were categorized in to four groups. The number of patients in each category is shown in Figure 3. 


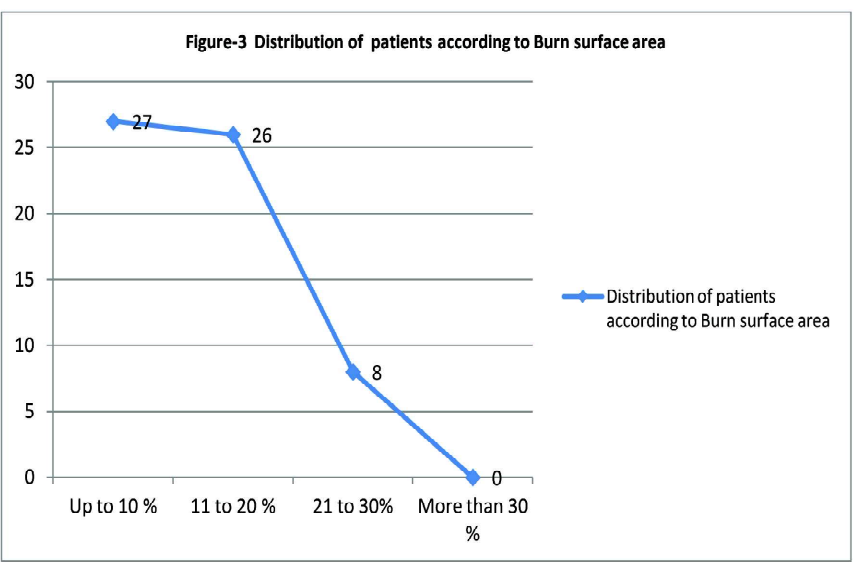

Figure 3 Distribution of patients according to burns surface area

\section{DISCUSSION}

The frequency of representation of children among burns victims admitted to hospital and their sex distribution in our study was similar to previous reports from elsewhere. ${ }^{5}$ Male children are at increased risk; may be because of their greater activity levels, risk taking behaviours and fire play. Predominance of lower age group children observed in our study was similar with another report which states that in India children in the age group of 0 to 5 years account for $50 \%$ of all childhood burns. ${ }^{6}$ Another study says that nearly a fourth of all burn injuries occur in children under the age of 16 years, of whom the majority are below the age of 5 years. ${ }^{7}$

Observation of scalding being the predominant cause of injury in this group was consistent with the Indore study ${ }^{8}$ which showed similar findings. This is in contrast from African study which reported that flame burns accounted for $57 \%$ and scalding only in $32 \%$ cases of childhood burns. ${ }^{9}$

All the ten victims of flame burns in our study were male children and they were above the age group of 5 years. This shows that younger children are more likely to sustain injuries from scalded burns that are caused by hot liquids or kitchen preparations while older children are prone for injuries from flame burns. Playing with matches and cigarette lighter, bursting of crackers were the main causes of flame burns in this study.

In the present study one case was a homicide in which the father poured kerosene on his 12 year old daughter and tried to burn. She escaped with $12 \%$ total body burn surface area. The reason was familial disharmony. Other than this no cases of child abuse was reported in our study. But to bring the child abuse cases to the light a careful investigation is required especially by a team comprising experts from fields of medicine, psychology, social work and law. In an analysis of paediatric burns admissions to a hospital in India during the years $1992-2007,{ }^{4} 9.3 \%$ of burn injuries were found to be secondary to abuse. According to another study, burns account for $10 \%$ of all cases of child abuse and majority of victims are less than 2 years of age where scalding is the most common cause. ${ }^{10}$
Among the study group 26 cases suffered from burns with less than $10 \%$ total body surface area and 27 cases suffered from 11 to $20 \%$ burns. No cases were reported with more than $30 \%$ burns and mortality was not reported. Mortality rate is nearly $100 \%$ only if the burns are affected with more than $40 \%$ total body surface area. ${ }^{11}$

\section{Key Preventive Tips}

Use safe cooking practices such as never leaving food unattended on stove. Supervise or restrict children from using of utensils with cooked food or boiled water or beverages. A water heater with pre-set at lower temperature in home will be a safe guard; possible in high income group families. Recognize burn hazards like children playing around open flames, unattended hot liquids, unattended heaters and traditional stoves. Impart community Education programmes focusing on reduction of such hazards, modification of environment like stable raised cooking surfaces and barriers to separate play and cooking areas.

\section{CONCLUSION}

Burns are preventable. Mortality and morbidity due to burns in developed countries is in a lower rate due to prevention strategies and improvement in care of burn cases. But in developing countries burn injury in children continues to be a major epidemiological problem. An intense campaign to make people aware of risk factors and their avoidance is required to reduce the number of burn accidents in children.

It is also essential to encourage the development of burn care systems including training the health care providers in managing people with burns.

Limitation of the study: Within all countries burn risk correlates with socioeconomic status and it was reported that people living in low and middle-income groups are at a higher risk for burns than people living high income groups. However, socio economic factors were not taken in to consideration in this study.

Acknowledgements: The authors are grateful to the Department of Medical Records and Burns and Plastic surgery, Jubilee Mission Medical College \& Research Institute, Thrissur, Kerala.

Conflict of interest: None declared.

Ethical clearance: Taken.

Source of funding: none declared.

Author disclosure: (1) The article is original with the author(s) and does not infringe any copyright or violate any other right of any third party. (2) The article has not been published (whole or in part) elsewhere, and is not being considered for publication elsewhere in any form, except as provided herein. (3) All author(s) have contributed sufficiently in the article to take public responsibility for it and (4) all author(s) have reviewed the final version of the above manuscript and approved it for publication.

\section{REFERENCES}

1. E Marty Knott, Daniel Jostlie, David Juang. Burns. In: 
George W. Holcoub III, J Patric K Murphy, Daniel J Ostlie. Ashcraft's Paediatric Surgery. London: Saunders Elsevier; 2014. p. 166-76.

2. Burns-Fact Sheet: WHO; 2016 Sep.

3. Ruth GD, Smith S, Bronson M, Davis AT, Wilcox RM Outcome related to burn-related child abuse: A case series. J Burn Care Rahabil 2003;24:318-21.

4. Mathangi Ramakrishnan K, Mathivanan Y, Sankar J. Profile of child abuse by burning. Ann Burns Fire Disasters 2010;23(1):8-12.

5. Amoldhopte, Tiwari VK, Patel Pankaj, Bamal Rahul. Epidemiology of paediatric burns and future prevention strategies- a study of 475 patients from a high volume burn centre in North India. Burns and Trauma 2017(5):5-8.

6. Atiyeh BS, Costagliola M, Hayek SN. Burn Prevention
Mechanisms and outcomes: Pitfalls, failures and Successes. Burns 2009;35:181-93.

7. Bayat A, Ramaiah R, Bhanankar SM. Analgesia and sedation for Children undergoing burn wound care. Expert Rev Neuro Ther 2010;10:1747-59.

8. Mukerji Gaurav, Chamania Shobha, Patidar GP, Gupta Saurabh. Epidemiology of paediatric burns in Indore, India. Burns 2001;27(1):33-8.

9. Sowemimo GO. Burn Case in Africa: Reducing the index of misery. J Burn Care Rehabil 1993;14:589-94.

10. Peck MD, Priolo Kapel D. Child abuse by burning: a review of the literature and algorithm for medical investigations. J Trauma 2002;53:1013-22.

11. Jean C Emmanuel. Primary Trauma care manual. In: Surgical care at the District Hospital, Geneva: World Health Organization, 2003. p PTCM 34-7. 